\title{
Multi-Competence, ELF, Learning and Literacy: A Reconsideration
}

\author{
Howard Doyle
}

\begin{abstract}
Cook's multi-competence model is taken as a basis for an approach to English education, taking advantage of biand multilingual learners' competences in other languages. This perspective mirrors what happens in English as lingua franca (ELF) situations and also in approaches to literacy education. In the latter, learners bring to the learning their pre-existing skills, knowledge and attitudes. Further, in the present digital age, learners frequently possess higher digital literacies than teachers, partly because they engage with electronic media and communication channels in their normal lives, which again is part of new multilingual and transnational online cultures. While traditional types of language learning are recommended to be maintained, the utility of bringing local language and literacy practices together with learners' own knowledge and skills is recommended for current and future learning of English. It is suggested that this approach is appropriate for new digital and other literacies relevant to modern information processing and communications technology.
\end{abstract}

Index Terms - English as lingua franca, learning, literacy, multi-competence model.

\section{INTRODUCTION}

Vivian Cook, a British applied linguist proposed his multi-competence model in the early 1990s developed from Universal Grammar theories. Multi competence relates to competence in two or more languages, which traditionally are understood as first and second or other languages (L1, L2, $\mathrm{OL})$. In this paper these a priori distinctions are not presumed. Rather connections are drawn among people's multi-competence in more than one language. Following on, Literacy which reflects considerable elements of language use, ELF (English as a lingua franca) and also relevant categorizations of Learning are deduced and drawn. The purpose is to establish coherent ground for a model for language education that is appropriate for meeting local modern and cultural needs.

\section{Multi-COMPETENCE}

The Multi-Competence model has evolved since its early inspiration from Universal Grammar:

The term 'multi-competence' was originally defined as 'the compound state of a mind with two grammars'; in the context of that paper, 'grammar' was used in the Chomskyan sense of the total knowledge of language in the mind (the I-language) leading some people to infer wrongly that multi-competence

Manuscript received June 15, 2014; revised August 14, 2014.

Howard Doyle is with the Dept. of International Studies, Kochi University, Japan (e-mail:hdoyle@kochi-u.ac.jp). was restricted to syntax. So multi-competence is now usually said to be 'the knowledge of more than one language in the same 'mind'. Multi- competence thus presents a view of second language acquisition (SLA) based on the second language (L2) user as a whole person rather than on the monolingual native speaker [1].

As mentioned before, distinction between L1 and L2 dissipates somewhat in the multi-competence view in as far as both influence each other. Cook refers sets of knowledge and skills becoming integrated, as per the continuum shown in Fig. 1 below. These have parallels regarding Literacy, discussed later.

However Cook's research has used orthodox Second Language Acquisition (SLA) theories as a starting point (and Cook is often cited within that field). His ideas therefore are useful here for trying to present an understanding of unorthodox perspectives from within the orthodox. As such, the core points of the multi-competence model relevant here are as follows:

- The L2 user has other uses for language than the monolingual, like code-switching and translation

- The L2 user's knowledge of the second language is typically not identical to that of a native speaker in syntax, vocabulary, etc.

- The L2 user's knowledge of their first language is in some respects not the same as that of a monolingual

- L2 users have different minds from monolinguals

- $\quad$ L2 users have slightly different brain structures [1].
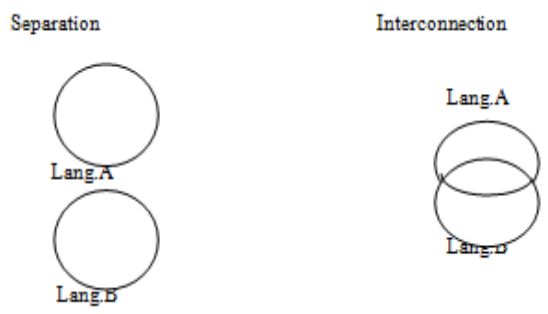

Integration

Fig. 1. Cook's integration continuum of possible relationships in multi-competence (Source: [2]).

Points 1 and 3 above, aligning people with L2 competence with monolinguals (ostensibly who lack such L 2 competence or linguistic repertoire) are the basis of proceeding discussions and proposals presented later, initially in relation to ELF. However there is yet one more claim by Cook which is also relevant: that multi-competence transcends individuals, affecting a (language) community - the knowledge of more than one language in the same mind or the community [2].

This is a contentious notion, and I believe it requires more investigation than has been done to now. For instance, to 
what extent can a language acquisition theory with roots in neuro- and psycholinguistics evolve into a model for societal language awareness? My view is that, with regards to language situations in a language community, Cook's multi-competency model informs rather than explains. Instead, multi-competency works better explaining the situations of individuals with bi- or multi-lingual consciousness.

\section{ELF}

At the start of a book entitled Global Interactions in English as a Lingua Franca, Franca Poppi [3] quotes Seidlhofer's [4] common definition of ELF, as Any use of English among speakers of different first languages for whom English is the communicative medium of choice, and often the only option

Yet, surprisingly, Poppi subtitles her book, How written communication is changing under the influence of electronic media and new contexts of use. The significance is in the paradox of Poppi projecting her investigation into current and future trends of language use and relevant literacies in digital fields, but relies on a conventional ELF definition referring to English users as 'speakers'. This significance shall become clearer later when the 'digital native' phenomenon is discussed.

ELF also presumes English-plus-alpha. Rationale for this is frequency and ever-present chance of code-mixing and code-switching among varieties of English and also any other local languages. ELF is often seen as a thing or a cultural entity and even as a variety of English on its own [5]. Rather, ELF is better understood as a mode of English use, even governed by context of situation. For instance, people using or who resort to English in communication situations may be conscious of various, even unpredicted institutional, legal, political or other pressures to use English. But in the situation, people are also commonly intent on doing what they need to do, saying what they need to say. ELT discourses also sometimes incorporate ideas about a world lingua franca English variety that may act as a common tongue, which educated or powerful people and of course also native speakers use. For instance, the current Singapore Ministry of Education curriculum document states:

At the end of their primary and secondary education, pupils will be able to communicate effectively in English ... They will be able to: ...

- Speak, write and make presentations in internationally acceptable English that is grammatical, fluent and appropriate for purpose, audience, context and culture

- Interact effectively with people from their own or different cultures. ...

- 'Internationally acceptable English that is grammatical, fluent and appropriate for purpose, audience, context and culture' refers to the formal register of English used in different parts of the world, that is, standard English. [6].

However, leading ELF theorist, Jennifer Jenkins, has proposed that ELF varieties are characterised by core elements of English forms in which people need to be competent in order to be able to engage with English in at least a minimally comprehensible way. Jenkins [7] emphasizes phonological features of English. Yet, unless people have competence with syntactical and lexical aspects as well, use of any kind of English would be problematic or even not possible. Pragmatics awareness is another element, though it incorporates contextual cues and cultural awareness evident in protocols for maintaining face, things which vary far more significantly across cultures. In this sense pragmatic awareness acquired in conjunction with learning another language would reflect Cook's idea of multi-competence affecting 'the overall system of a [person's] mind or a community' rather than just a person's language knowledge.

ELF however presumes that people would have some competence with English and one or more other languages (or with multiple varieties of English). If there is any credence in the multiple-competence model then to engage in ELF is potentially to utilise competences that come with having the option to think in line with, even use, more than one language.

\section{LEARNING}

Following on from ELF, Learning is relevant, in that people would learn English as they would learn any language. Language Learning and language Acquisition are seen as different [8], partly due to the more conscious and focussed character of learning as a process. However in the learning typology below, acquisition is considered alongside learning as leading to the same outcome: obtaining knowledge, skill, competence, with English, language and other things too.

- Institutional - for instance school-based learning subject to curriculum and language policy (not always governmental, but also corporate, religious, clubs, workplace, etc.). Teaching as a way of learning obviously is pervasive. Institutional learning is also characterised by minimal range of learner choice about the learning.

- Non-institutional - this learning type is subject to people's choice; for instance independent learning, taking advantage of available opportunities and resources, and investing in or creating new ones.

- Unintentional - contact with or exposure to language in the environment, such as mass media or from people around a person. People 'picking up' language items, a linguistic sense or awareness, systematically or unsystematically, consciously or unconsciously, can be learning unintentionally. On this point un- or sub-conscious acquisition can be considered to be occurring.

The utility of this typology is made apparent below.

\section{LITERACY}

Anthropological research in rural Iran in the 1970s by Brian Street [9] showed how literacy practices were evident in communities in which literacy had been presumed non-apparent: in Koranic religious schools with Arabic, in state school education with Farsi and numeratic practices in local urban agricultural markets. He and others draw the literacy practices idea from Heath's [10] work in a similar 
context in isolated mountain communities in south east USA, in which she developed the Literacy Event concept: basically, an event when people interact with written text. A Literacy Practice is what people do in a literacy event. Street, writing in the early 1980s, prefers rightly or wrongly, an 'ideological' model of literacy that recognizes a multiplicity of literacies; that the meaning and uses of literacy practices are related to specific cultural contexts; and that these practices are always associated with relations of power and ideology, they are not simply neutral technologies [11].

Further, Street adds to his view on cultural specificity of literacy practices by identifying

Dominant literacies originat[ing] from the dominant institutions of society. [And] Vernacular literacies hav[ing] their roots in everyday life [12].

A more guarded, even realistic interpretation is that literacy practices often can be culturally specific, but certainly not all. More to the point is that any agenda incorporating literacy education ideally should incorporate relevant practices specific to any given culture or community. This parallels similar latter-day points mentioned in the preceding section about local language influences on local ELF by Canagarajah [13] and Pennycook [14].

\section{NeW MEdia, NeW Literacy Practices AND NEW LANGUAGE FORMS}

It is from here that a key point in this paper can be introduced. People engage in each of the above-listed types of learning at different times in their lives. It is here that the point in Franca Poppi's book's title - communication 'changing under the influence of electronic media and new contexts of use - comes to bear. There are new types of media, new communication goals, purposes and even interfaces.

For instance, older people, say currently in 2014 over 25 years of age, including perhaps most teachers, were mostly brought up under the presumed primacy of the need to master skills needed for written text. Over a decade ago, Mark Prensky [15] coined the expression Digital Native, people who grew up with new literacies for new media. A similar term, 'Net Generation', is mentioned in a recent UNESCO-sponsored document about new literacies [16]. Poppi [3] mentions new ways of reading and writing plus navigating hypertext online as part of these new literacies, which tend to blend traditional print literacies and which may also be used simultaneously. Ironically, if younger people (learners) are the digital natives, older people (teachers) may well be digital non-natives. As the older generation shift to new, digital literacy practices, they become in Prensky's [15] words, "Digital Immigrants". Ryu [17] considers digital natives in his research on online game players who also form interactive transnational communities. After playing games members communicate discussing, inquiring and advising each other in forums and on discussion boards about their electronic games [17]. These communities are characterised by their international and multilingual membership with their accompanying "multiplicity of language" [17], and attendant "multilingual literacy". Even so, Ryu observed that his subjects "used English as lingua franca, a common language" [17]. Members require digital literacy skills to be able to communicate (let alone play) with each other. He calls on language teachers and education planners to recognize digital literacy and to incorporate use of digital media in curricula. He recommends recognizing digital natives' non-institutional language learning and activity as viable, relevant ways to learn, based in these young learners' own cultural interests and literacy practices. A similar call is made by Lee [16], though for a more institutionalised structured learning approach.

Language as a component of literacy occurs in as far as literacy practices involve engagement with language texts (and with non-language texts too: eg. graphics, video and audio), for which most people purposefully learn language. Another aspect of literacy is meta-cognition and rubrics ideally a person should be able to know and to articulate what they are doing, most effectively done using language. In this sense also, language - say English - is used also to articulate literacies that people are going to learn (referred to as 'Meta-language' here). Any relevant syllabus, curriculum document or textbook is an example of this. Many textbooks explaining literacy skills and practices even do so in language that is more complex than actual language required for engaging in those practices. In other words, lesson and textbook explanations can be less comprehensible than what they would teach. With English textbooks this is a problem! This issue affects the utility of institutionalised learning in many, many fields. Further, language and literacies from outside of a given culture can have problematic transfer and take-up by people of that culture. I have tried to demonstrate this earlier with reference to younger digital natives, their relative savvy with new digital literacies and a gap between their non-institutionalised learning and established institutionalised learning apparati administered and preferred by many older education practitioners.

What to do about it? Viable solutions are already available.

\section{A NECESSARY NEW DichotomizATION OF ENGLISH}

In this paper I have tried to show how people can be psychologically set for dealing with language in different ways, given operation of Cook's multi-competence model. Not all people though, for instance monolinguals. Yet for a person in a given ELF context, English can be just one available language for communication. For the individual, this condition exists before and during the point when English becomes the common language mode of communication participants for achieving their communication or other goals, to do what they have to do.

Further, though earlier twentieth century literacy studies identified multiple traditional literacies among diverse sets of literacy practices which people engage in on a daily basis, people now can select appropriate channels or media and integrate literacies required for their operation. This is noticeable in electronic media and computer mediated literacy practices requiring multiliteracies to navigate successfully. A peculiar characteristic of this technology is the predilection for young people to have learned or acquired necessary literacies in more unstructured ways than through institutional learning, often by need or choice, and also unintentionally. Such communities frequently are 
multilingual, and English frequently pervades as common language on online media. This may presume that many or most members bring competence and also literacies from their other language backgrounds.

On this last point, Andy Kirkpatrick's [18] proposal for a Multilingual Model for teaching English has relevance. Kirkpatrick writes for the context of the Association of South East Asian Nations (ASEAN) for which he is more interested in traditional printed text and spoken modes. At a fundamental level, he notes that

While certain features of standard English may be unnecessary for an ELF syllabus, some non-standard features can be useful for lingua franca communication [18].

Kirkpatrick raises two predictable questions providing two unorthodox answers:

- What variety of English should be taught and how? Rather than focussing on a specific variety of English, ... a radical move to teach English as it is used in social contexts [within the ASEAN region].

- Who should teach English [?] ... suitably trained multilingual teachers with high levels of English proficiency [18].

Kirkpatrick refers to an ELT project in Indonesia in the early 2000s [18] involving Australian and local institutional input, producing a syllabus and textbook rooted in the local community, its customs and culture.

Yet, the same principles can apply to literacy education, especially if it integrates multiple communication modes and media as electronic literacy practices do. To shift focus in this direction means to shift focus away from traditional or orthodox models of English taught, such as from general or generic English to more localised and more specific modes, practices and contexts. There is already a significant effort directed this way in face-to-face, print and also electronic media: in any Content-based English (often for higher proficiency levels anyway) and also English for Specific Purposes (ESP), These include things like business English [3] and other work or vocational English programs. They commonly and necessarily incorporate de facto literacy components. Significantly also, English that is taught often is contained within an identifiable corpus, or at least with a core corpus of essential English forms and functions.

Here lies the proposed dichotomization:

- Generic mutable English depending on local circumstances. 'British', 'American', 'Business', 'World', are orthodox adjectives describing these Englishes already. 'Local' of course is not just proximally local - where a person is. 'Local' implies real and virtual (eg. digital) communities of which people are members, and people may be members of more than one community at any given time. In this case, the focus would be more on English for its own sake.

- The second aspect is subsumption of English as a component of literacy practices where appropriate. This can facilitate people learning English as part of what people need or want to learn or do, as opposed to what they do not need or want.

I believe both aspects mentioned here are viable within institutional and also non-institutional learning situations as outlined earlier.

\section{CONCLUDING POINTS}

I do not propose removing existing general English education approaches or infrastructure. That is in spite of their construction more around the cultures and contexts of the learners' as a more workable way, rather than based on some foreign or imaginary world standard English variety. To this extent, existing institutional, non-institutional and indeed unintentional learning milieux should remain - people frequently learn what they have to learn in spite of obstacles in their situation.

I do propose one step further: making the English secondary to the literacy and other skills or knowledge needed to be learned. Flippant inversion of ESP to make 'SPE' (Specific Purpose English) is one way to articulate this. Any such particularized program most likely would need a pre-requisite knowledge or a minimum operating English meta-language repertoire for literacies peculiar to the content and learning goals. However, local language and literacy practices can assist this mediation, and scope for incorporating them would need to be included.

There is one final issue: can the local - local English variety, local language, local literacy practice, local texts and other cultural artifacts - be used for general English, in an ELF sense? I believe so, along the lines of Kirkpatrick's Multilingual Model. There is also the question of teaching/learning lingua franca Englishes outside of any given local community. This is also possible and frequently demonstrated in ELF research. There is a limitation however: in as far as language cultures are defined ethnologically or geographically: these perspectives become secondary as people interact across those cultural boundaries within more newly-formed cultures defined more by mutual interest and purpose, such as business [3], vocation, leisure or religion.

How people bring baggage from their own cultures perhaps is more evident in pragmatics aspects of language than in other aspects like syntax, lexis and phonology. These latter aspects are more easily formalised, codified and taught. This characteristic makes these aspects easier to focus on, therefore easier to teach or prescribe. English forms are more easily transferable to a literacy-type learning program, but bring into being just part of the outcome and not an end in themselves. Yet, competence in more than one language can enhance the uptake of another, in ways that the Multi-competence model shows. The concluding point in this paper is that in English education, institutions and also the learners should not shy away from local discourses and other influences, purposes or goals. Instead being able to embrace them in a complementary way can only be more utilitarian than detrimental in a holistic sense.

\section{REFERENCES}

[1] V. Cook. (2012). Characteristics of L2 Users. [Online]. Available http://homepage.ntlworld.com/vivian.c/SLA/Multicompetence/

[2] V. Cook. (2012 a). Multi-Competence. [Online]. Avaialable: http://homepage.ntlworld.com/vivian.c/Writings/Papers/MCentry.htm

[3] F. Poppi, Global Interactions in English as a Lingua Franca, Bern Peter Lang. p. 15, 2012. 
[4] B. Seidlhofer, Understanding English as a Lingua Franca, Oxford: Oxford University Press, p. 7, 2011.

[5] H. Doyle, "What is ELF: finding discursive focus for English-as-a-Lingua-Franca Debate," Research Reports of Department of International Studies, Faculty of Humanities and Economics, Kochi University, 2013.

[6] English Language Syllabus 2001, Curriculum Planning and Development Division, Ministry of Education, Singapore, p. 3. Italics mine: the italicized segment is re-produced in English Language Syllabus 2010: Primary \& Secondary (Express/Normal [Academic] Curriculum Planning and Development Division, Ministry of Education, Singapore, p. 14.

[7] J. Jenkins, The Phonology of English as an International Language, Oxford: Oxford University Press, 2000.

[8] S. Krashen, Second Language Acquisition and Second Language Learning, Pergamon, 1981, First Internet Edition December 2002.

[9] B. Street, Literacy in Theory and Practice, Cambridge: Cambridge University Press, 1984.

[10] S. Heath, Ways with Words: Language, Life and Work in Communities and Classrooms, Cambridge: Cambridge University Press, 1983.

[11] B. Street, "Cross-cultural perspectives on literacy," in Language and Literacy in Social Practice, J. Maybin Ed, Clevedon: Open University Press, pp. 139-150, 1994.

[12] B. Street, Cross-Cultural Approaches to Literacy, Cambridge: Cambridge University Press, Quoted in D. Barton, Literacy: an Introduction to the Ecology of Written Language, Oxford: Blackwell 1994, p. 39.

[13] A. Canagarajah, "Negotiating the local in English as a lingua franca," Annual Review of Applied Linguistics, vol. 26, pp. 197-218, 2006
[14] A. Pennycook, "Pluralithic Englishes: towards a 3-D Model," in Global Englishes in Asian Contexts: Current and Future Debates, $\mathrm{K}$. Murata and J. Jenkins Eds., Basingstoke: Palgrave Macmillan, Pennycook specifically refers only to 'language' but not to 'English' in his diagrammatic Pluralithic model for ELF, pp. 194-207, 2010.

[15] M. Prensky. (2001). Digital natives, digital immigrants. Part 1 On the Horizon. 9(5). Digital natives, digital immigrants. Part II Do they really think differently? On the Horizon. 9(5). (Retrieved on 30 April 2014) [Online]. Available: http://www.marcprensky.com

[16] A. Lee, "Literacy and competencies required to participate in knowledge societies," in Conceptual Relationship of Information Literacy and Media Literacy in Knowledge Societies, A. Lee, J. Lau, T. Carbo, and N. Gendina, Series of Research Papers, World Summit on the Information Society (WSIS) Paris: UNESCO, p. 5, 2013.

[17] D. Ryu, "Non-native English speakers' multiliteracy learning in beyond-game culture: a sociocultural study," MERLOT Journal of Online Learning and Teaching, vol. 7, no. 2, June 2011, pp. 231-243, 2011.

[18] A. Kirkpatrick, English as a Lingua Franca in ASEAN: a Multilingual Guide, Hong Kong: Hong Kong University Press, 2010.

Howard Doyle comes from Sydney in Australia, Currently he is an associate professor in the Department of International Studies at Kochi University in Japan. His research interests are the ecology of English in the world, language and literacy education, pragmatics and text analysis 